\title{
"Study of Mechanical Property and Characterization of Copper-graphite Metal Matrix Composite Prepared by Powder Metallurgy Route"
}

\author{
Rahul srivastava, Er. Sunita Rajbhar
}

\begin{abstract}
In this chapter author make to study of copper-graphite metal matrix composite for fulfill the need of future requirements. This composite material prepared by the path of powder metallurgy. A Copper-graphite metal matrix composition posses the properties of copper likes as excellent thermal electrical conductivity \& low strength and graphite likes as solid lubrication, small thermal expansion coefficient. In this composite material is prepared by change the $\%$ of graphite reinforcement. This is varying from $2 \%, 4 \%, 6 \% \& 11 \%$ vol. of graphite. A test is conduct to check the mechanical properties \& characterization of composite. $\mathrm{Cu}-4 \%$ volume of graphite gives the better overall performance as compared to other for sintering at $700 \mathrm{MPa}, 690-700 \mathrm{CC}$ at $1 \mathrm{~h}$.
\end{abstract}

Index Terms - Copper, graphite, sintering, SEM, mechanical properties, etc.

\section{INTRODUCTION}

Metal matrix composites (MMCs) are most requirements for new generation engineering materials. Even though they have been used recently, but due to their useful qualities such as specific strengths, specific rigors, wear resistance, corrosion resistance and elastic modulus etc., they have a great effect. Copper is most commonly used as an industrial and functional metal for thermal. When $\mathrm{Cu}$ is used as an electrical connection, the mechanical properties lead to the wear of the component. Since graphite has very good electrical conductivity, when it is reinforced in $\mathrm{Cu}$, mechanical properties are greatly improved. Graphite is a solid lubricant that reduces the wearing of $\mathrm{Cu}$-graphite MMC.There are some many application likes as bearing material and brushes due to its good thermal \& better electrical conductivity, also favorable self- lubricating performances on the bases of strength. Complex composite parts are made by injection moulding. Advanced composites are constructed using these polymers with strong fibres such as carbon and Aramid reinforcement. These composites contain applications in aircraft, automotive industry. The limitations of polymer matrix composites at high temperatures can be recovered using metal matrix composites. The combination of reinforcement \& matrix also depends on strengthening the mechanism. SPS gives is better \& advanced technology as compared o the conventional sintering. The chemical reaction \& interaction between the reinforcement \& the matrix component determines the characteristics of the overall component, interface adhesion, and significantly affects

Rahul srivastava, M.tech Student, Department of Production Engineering, S.R Institute of Technology \& Management Lucknow, India

Er. Sunita Rajbhar, Assistant Professor, Department of Production Engineering, S.R Institute of Technology \& Management Lucknow, India mechanical properties. The wear properties of pure copper are less than the wear properties of $\mathrm{Cu}$-graphite $\mathrm{MMC}$.

A. Study of objective \& aims of current composition:-

1. Construction of copper-graphite composite by Route Powder metallurgical route.

2. Improving the mechanical properties of the whole by using various sintering techniques like traditional and spark plasma sintering.

3. Impression of various sintering parameters like as temperature, pressure \& time etc.

4. Study the interface between $\mathrm{Cu}$ and graphite.

5. Characteristics Study the characteristics of overall wear.

6. Impact and optimization of various sintering parameters like temperature, time and pressure etc.

7. Physical properties, such as the measurement of density of sintering composite overall by Archimedes theory.

8. Cause of graphite and copper powder milling to increased interfacing bonding.

9. Failure analysis of composites fabricated by compression and three-point turn tests.

10. Improved wear resistance of fabricated composites.

\section{LITERATURE}

So many researcher researches on this topic are as follows:

1. S.F. Mustafa et al. (2002) studied friction and wear of $\mathrm{Cu}$-graphite composites produce by $\mathrm{Cu}$-coated and non-coated -graphite powder. They have shown that composites produce by $\mathrm{Cu}$-coated and uncoated graphite have minimum wear rates and friction coefficients compared to pure copper fabric, which can be attributed to the fact that the slip of wear samples on the surface serves as a graphite layer, solid lubricant. Coefficient of friction of graphite material used, while the rate of wear decreases. 2. S. Arvindan \& k. rajkumar (2009) study about the microwave sintering of $\mathrm{Cu}$-graphite composites. Coarser microstructure with large porous is achieved by this traditional sintering process which reduces power, as well as resistance. In microwave sintering, heat is produced internally within the material and the sample becomes a source of heat.

3. A. Yeoh. et al provided the expansion of the cylindrical sample is seen in both the lateral and longitudinal dimensions with the maximum expansions measured for composites in the 50 volume \% copper-50 volume \% graphite ranges. Spheroidization is due to result of non-wetting between Cu-graphite.

4. Simon Dorfman and David Fuxb (1996) studied the stability of copper separation at the $\mathrm{Cu}$ - carbon metal-matrix composite interface under alloy. The stability of the interface in MMCs is related to the conditions of isolation of metal 


\section{"Study of Mechanical Property and Characterization of Copper-graphite Metal Matrix Composite Prepared by Powder Metallurgy Route"}

alloy in metal -fiber interfaces. It has been shown that alloy of matrix; interstitial metal-metalloid replaces copper in a solid solution, replaces the value of mixing energy.

\section{EXPERIMENTAL DETAILS}

Samples of copper-graphite MMC is made by path of conventional powder metallurgy such as blending, compaction \& finally sintering, etc. Formation of composite was made by two sintering method (spark plasma \& conventional sintering) to study the various mechanical \& characteristic properties of the composite. In this process, we take pure copper powder of 100 gram mixed with the volume fraction of graphite such as $2 \%, 4 \%, 6 \% \& 11 \%$ respectively. Then they are blending together properly used by mortar \& pestle for 25-30 minute. Easy to check perfect distribution of graphite particle in over all copper matrix. The samples are cold compacted by applying load of $600 \mathrm{MPa}$ for 3 minute in a diameter of $30 \mathrm{~mm}$.

\section{A. MATRIX:}

Metallic matrices are most important components for the formation of metallic matrix composites (MMCs). The selection of matrix material depends primarily on temperature, strength, density and cost requirements for desired applications. Other factors, such as flexibility, electrical conductivity, fatigue resistance and fracture toughness depend on the selected metal. One of the most essential factors is the compatibility of the matrix material with reinforcement. In this case, compatibility means that there will be no undesirable chemical reaction in the interface between matrix and reinforcement. Metal matrix composite can be classified into following ways. One classification is the consideration of type and contribution of the reinforcement in particle, fiber, layer and penetration composite materials. Pure metals are generally not considered as matrix materials for MMCs, because the properties of pure metals are not attractive.

\section{B. REINFORCEMENTS:}

Reinforcement is either in the form of continuous fibers or in the form of discontinuous reinforcements such as whiskers, particulate, chopped fibred or platelets. Metal-matrix composites can be made by combining discontinuous or continuous or both of these reinforcements. The one of most advantage of the discontinuous reinforced composites leads to continuous ones is that they can be prepared using processing techniques, which are usually used for unchanged matrix materials, making them more cost effective. In some extra, discontinuous reinforced composites have good isotropic properties than continuous reinforced composites, which are due to the low aspect ratio and more random orientation of reinforcement.

Better adhesion properties between matrix \& fiber are obtained by essential wetting. Better wetting condition is provided by the strong relationship between fiber atoms. As a result of this interaction, there may be an undesirable effect: (1) the particle in the matrix or dissolution of fiber or (2) the creation of unwanted, uncontrolled and brittle compound. The chemical reaction $\&$ interaction between the reinforcement $\&$ the matrix component determines the characteristics of the overall component, interface adhesion, and significantly affects mechanical properties. The construction of the interface between the reinforcement and the matrix phase has substantial impact on the characteristics and production of metal composite material. The adhesion of both phases is examined due to interaction between them. In during the production of molten matrix with intrusion, wetting becomes important.

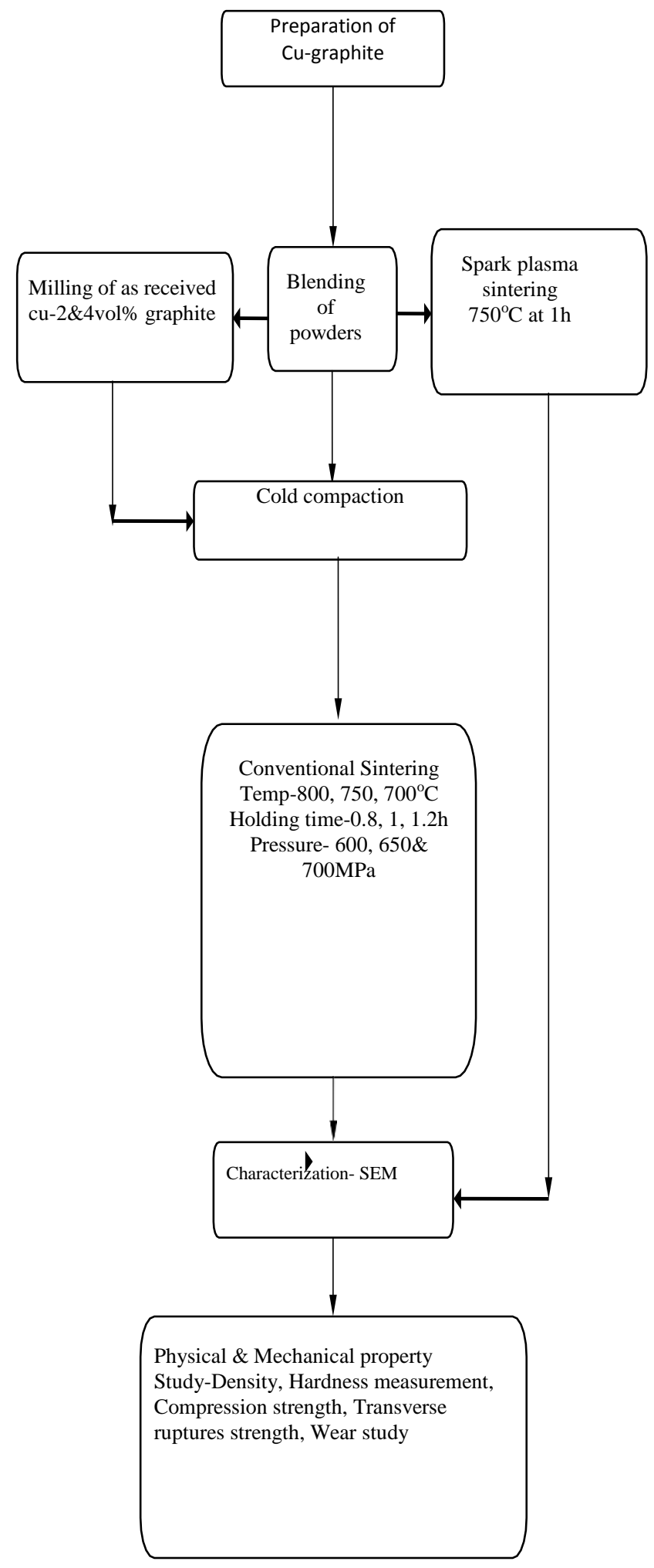

\section{RESULTS \& DISCUSSION}

\section{Characterization of composite:}

Particle size analysis: - The particle shape \& size of taking copper $\&$ graphite powder was determined by the particle size analysis. The particle size distribution of $\mathrm{Cu}$-graphite powder, 
International Journal of Engineering and Technical Research (IJETR)

ISSN: 2321-0869 (O) 2454-4698 (P) Volume-9, Issue-6, June 2019

average size of $\mathrm{Cu}$ is 30 micron \& size of graphite is 35 micron. It also characterized by SEM to get idea about the size $\&$ shape of powder particle. The flaky size of graphite $\&$ dendrite structure of $\mathrm{Cu}$ powder can be observed from micrographs indicator. In fig. $1-\mathrm{a}, \mathrm{b} \& \mathrm{c}$.

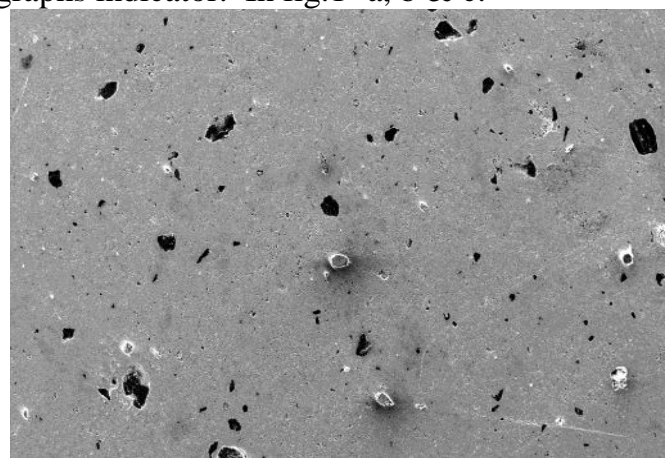

(a) $\mathrm{Cu}-2 \%$ of graphite by SPS

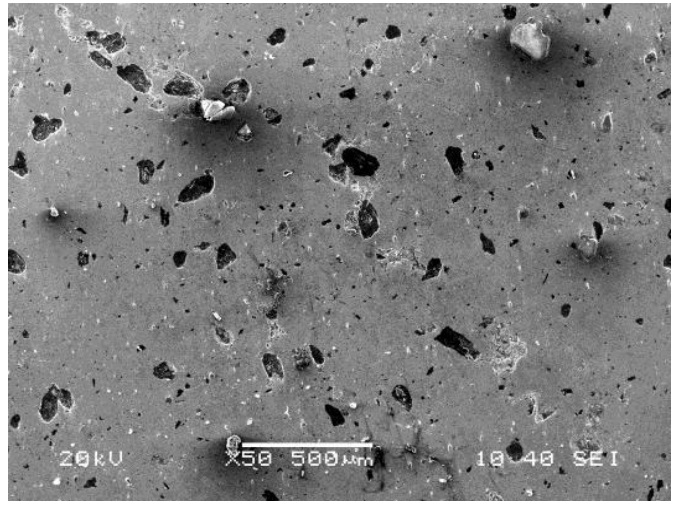

(b) $\mathrm{Cu}-4 \%$ of graphite by SPS

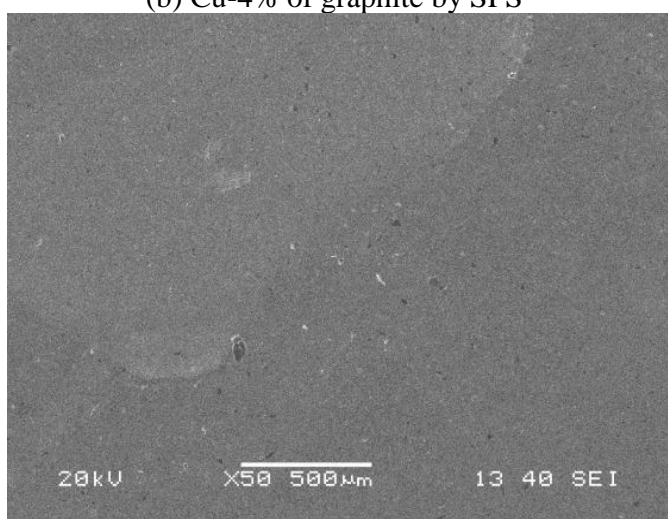

(c) $\mathrm{Cu}-4 \%$ graphite by milling

Pure copper is less than the $\mathrm{Cu}-4 \%$ volume of graphite by conventional sintering is less than the $\mathrm{Cu}-2 \%$ volume of graphite (spark plasma sintering) is then the $\mathrm{Cu}-4 \%$ volume of graphite by spark plasma sintering.

\section{MECHANICAL PROPERTIES}

\begin{tabular}{|l|l|l|}
\hline $\begin{array}{l}\text { Hardness } \\
\mathrm{Cu}-4 \% \text { vol. } \\
\text { of } \\
\text { graphite. }\end{array}$ & $\begin{array}{l}\text { Effect of } \\
\text { time }\end{array}$ & $\begin{array}{l}\text { The maximum hardness value at } 1 \mathrm{~h} \text { of } \\
\text { sintering. So, the result of 0.8h for } \\
\text { sintering timing is under sintering \& also } \\
\text { the result of 1.2h for sintering timing is } \\
\text { over sintering. Maximum hardness value is } \\
73 .\end{array}$ \\
\cline { 2 - 4 } & $\begin{array}{l}\text { Effect of } \\
\text { pressure }\end{array}$ & $\begin{array}{l}\text { That the maximum hardness is achieved } \\
\text { under the compression pressure of } \\
700 \mathrm{MPa} . \\
\text { After this discontinuity occurrence. } \\
\text { Maximum hardness value is 90. }\end{array}$ \\
\cline { 2 - 3 } & $\begin{array}{l}\text { Effect of } \\
\text { temperature }\end{array}$ & $\begin{array}{l}\text { After the } 700^{\circ} \mathrm{C} \text { hardness value of } \\
\text { materials are decreased. Maximum } \\
\text { hardness value is } 68 .\end{array}$ \\
\hline
\end{tabular}

\section{TRANSVERSE REPTURE STRENGTH}

The maximum bending strength \& minimum elastic modulus in copper- $4 \%$ volume of graphite in the metal matrix composite. When volume of graphite percentage is decrease then increase the maximum elastic modulus of the material are achieved. Modulus of composite is $16 \mathrm{MPa} \&$ maximum stress is $300 \mathrm{MPa}$. In fig. 2 (a)

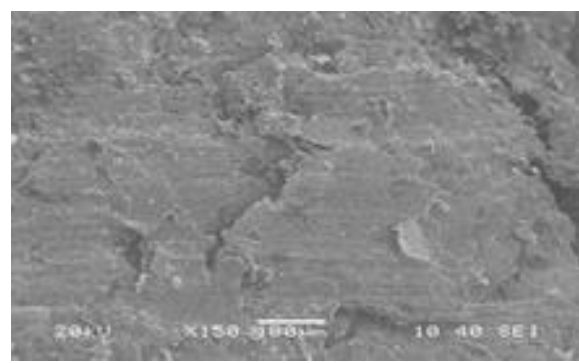

Fig.2 (a) after rapture due to compression

\section{WEAR STRENGTH}

The wear properties of pure copper are less than the wear properties of $\mathrm{Cu}$-graphite MMC. The adhesive property \& self- lubricant film of graphite comes to wear surface. Pure copper is less than the $\mathrm{Cu}-4 \%$ volume of graphite by conventional sintering is less than the $\mathrm{Cu}-2 \%$ volume of graphite (spark plasma sintering) is then the $\mathrm{Cu}-4 \%$ volume of graphite by spark plasma sintering. The main key factor of the sliding surface of samples is the thickness of graphite film, so they increase the wear resistance of $\mathrm{Cu}$-graphite composite.fig.3.c

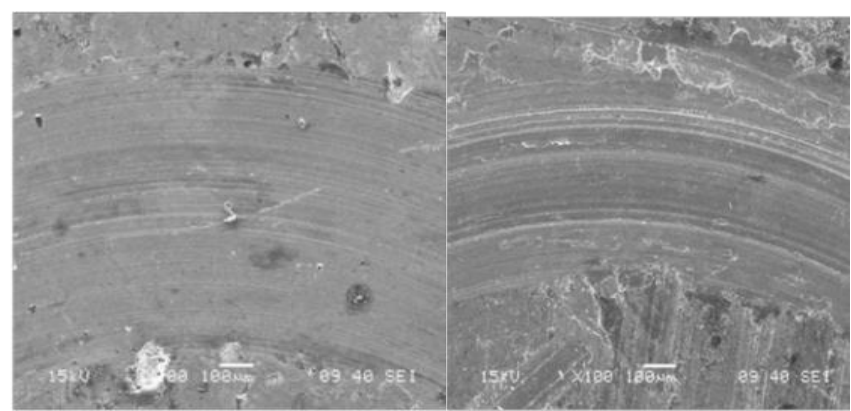

(A) $\mathrm{Cu}-4 \%$ graphite (SPS)

(B) $\mathrm{Cu}-4 \%$ graphite(CS)

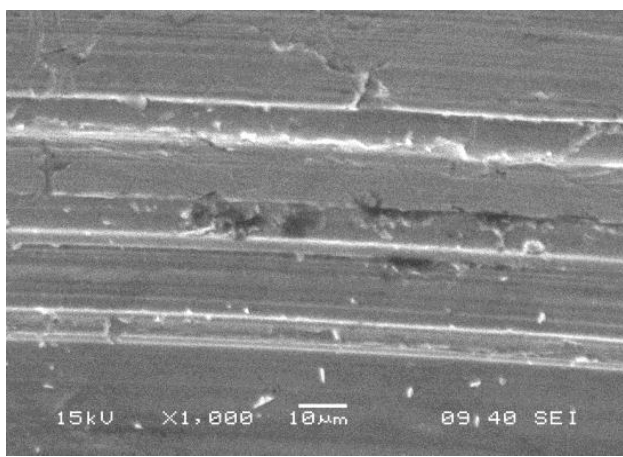

(C) $\mathrm{Cu}-4 \%$ of graphite

\section{COMPRESSIVE STRENGTH}

On the bases of above fig.4 (a), If the graphite percentages in the composite are increase then immediate decreased of compressive strength due to increase the brittleness nature of material. The maximum compressive strength of $\mathrm{Cu}-4 \%$ of volume of graphite composite material is $850 \mathrm{MPa}$. 


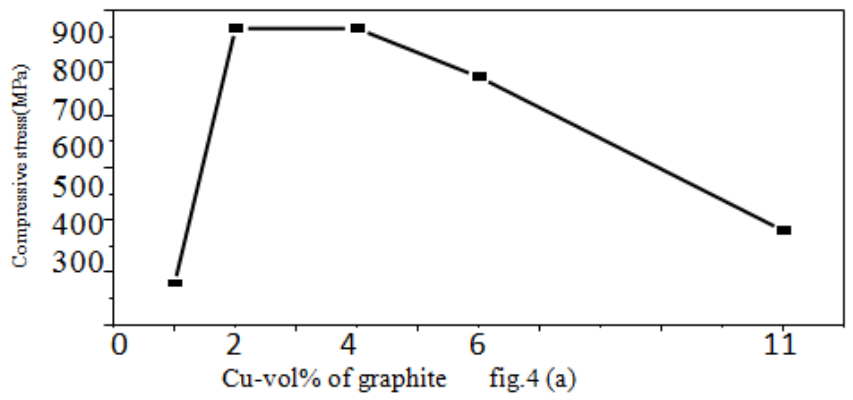

\section{CONCLUSION:}

1. The $\mathrm{Cu}$-graphite $\mathrm{MMC}$ was successfully made by both SPS as well as conventional sintering.

2. SEM analysis provides the better bonding between graphite reinforcement \& copper matrix.

3. The maximum sintering time, pressure \& temperature are 1 hour, $700 \mathrm{MPa} \& 700^{\circ} \mathrm{C}$ in conventional sintering.

4. When volume of graphite percentage is decrease then increase the maximum elastic modulus of the material are achieved.

5. The graphite (after the $4 \%$ ) percentages in the composite are increase then immediate decreased of compressive strength due to increase the brittleness nature of material.

6. $\mathrm{Cu}-4 \%$ volume of graphite by spark plasma sintering is optimum wear resistance.

7. Increased the wear resistance was seen by maximum percentage volume of graphite by SPS samples.

\section{SCOPE OF THIS PAPER:}

1. It helps the study of coefficient of friction \& effect of load.

2. It helps to understanding the wear rate, wear volume $\&$ wear mechanisms.

3. It also measures the electrical conductivity of copper-graphite MMC.

4. Copper-graphite MMC can also be made by microwave sintering.

5. It help to understanding of better mixing method are used during the composition

6. It helps to improve the overall performance of composite material.

\section{REFERNCES:}

[1] S. \& Fuks D., Dorfman,, "to study Stability of copper segregations on $\mathrm{Cu}-\mathrm{C}$ MMC interfaces under alloying", Composites Science and Technology in 1997.

[2] http://www.iitk.ac.in/biomaterialslab/Spark\%20Plasma\%20Sintering $\% 20-\% 20$ Fundamentals.pdf

[3] http://en.wikipedia.org/wiki/Sintering\#Sintering_mechanisms.

[4] Kovacik, J., Emmer, Kelesi, Lubomır, Stefan, Bielek, J., "Effect of composition on friction coefficient of $\mathrm{Cu}$-graphite composites" in 2008.

[5] http://www.iitk.ac.in/biomaterialslab/conventional\%20Sintering\%20 $-\% 20$ Fundamentals.pdf . 